\title{
Bibliografia de Sílvio Coelho dos Santos
}

\author{
Marcia Medeiros de Lima
}

Bolsısta de Aposo Tecnıco/Cnpq (AT/CNPq)

\section{Artıgos e comunicações}

I Rio Vermelho uma Povoa do Interior da Ilha de Santa Catarına Boletım da Comissão Catarnense de Folclore Florianopolis ano 14 n 27/28 1963

2 Os Grupos Jê em Santa Catarına Faculdade de filosofia ciêncıas e letras da UFSC Florianopohs 1963

3 Antropologıa ciência e preconceito O Estado Textos de Antropologıa FAFI/UFSC Florianopolis 19931966

4 A Educação Prımana Munıcıpal CEPE Faculdade de Educação da UDESC Florianopolis 1963

5 Os Indıos Xokleng e o Antropologo Arquivos do Instıtuto de Antropolo gıa da Unıversıdade do Rıo Grande do Norte v l n 2 Natal 1964

6 Dados Basıcos para a Delımıtação da Sub Area Cultural dos Campos de Lages CEPE Faculdade de Educação da UDESC Florıanopolıs 1964

7 Povo e Tradıção em Santa Catarına CEPE Faculdade de Educação da UDESC EDEME Florıanopolıs 1971

8 Areas Suburbanas e Marginaıs de Florlanopolıs CEPE Faculdade de Educação da UDESC Florıanopolıs 1965

9 Os Xokleng hoje Cadernos de Blumenau Tomo VII n 2 Blumenau 1965

10 Prelıminares para a compreensão do desenvolvimento do processo edu cacıonal no Vale do Itajaı do Norte CEPE Faculdade de Educação da UDESC Florianopolis 1965

11 A escola cm duas populações trrbais Revista de Antropologıa v 14 São Paulo 1966

12 Sobre mudança cultural entre os indıos Xokleng do Vale do Itajaı $\mathrm{Ct}$ ência e Cultura São Paulo v 18 n 31966

13 Sobre a integração econômica dos Indios Xokleng na Sociedade Regıo nal Anaıs do Instıtuto de Antropologia Florianopolıs 1968 
14 Indigenas de Santa Catarina Historia de Santa Catarma Grafipar Parana 1970

15 A zona rural da lha de Santa Catarma Ensaios sobre Sociologia e Desenvol vimento em Santa Catarna, EDEME Florianopolıs 1971

16 A sıtuação dos undıgenas do Sul do Brasıl' In COMUNICAÇÃo A XXIII REUNIÃO DA SBPC 231971 Anaıs Florlanopolıs Socıedade brasıleıra progresso a ciência Florianopolıs 1971

17 Grupos tribais sobreviventes no Sul do Brasil Anats do museu de antro pologia Flonanopolıs n 61973

18 Sobre a exıstência dos Indıos Xokleng arredıos na Serra do Tabuleıro Anars do Museu de Antropologia Florianopolis v 51972

19 Assıstência e sobrevivência de indıgenas no Sul do Brasıl In COMUNI CAÇÃO AO ENCONTRO INTERNACIONAL DE ESTUDOS DE PROBLE MAS BRASILEIROS 1 São Paulo 1972 Anals São Paulo 1972 Anats do Museu de antropologia Florianopolis v 41973

20 The Situation of the Indians of Southern Brazll The Situation of Indian in South Amenca Contributions to the Study of Inter ethnic Conflict The non Andean re gion of South America Geneva World Councl Churches 1972

21 Bases de trabalho de Pesquisador Cientifico Anats do museu de antropo logia, Flonianopolis ano 7, p 7261974

22 A Antropologia como ciêncıa no contexto da Universıdade em Santa Catarma Anals do Museu de Antropologia Florianopolıs ano 8 p 125 134, 1975

23 Metodologia Cientıfica Basıca Publicações avulsas UFSC Florianopolıs, 1975

24 Massacre Revista do Homem Ed Abrll São Paulo anol n 9 ano I , 1976

25 O Antropologo e os Indios no Sul do Pars In SEMINARIO O INDIO BRA SILEIRO UM SOBREVIVENTE I 1977, Anals Porto Alegre UFGRS 1977

26 Indigenas sobreviventes do Sul do Brasil In SIMPOSIO NACIONAL DE ESTUDOS MISSIONEIROS 21977 Santa Rosa Anals Santa Rosa out 1977 Revista Brastletra de Soctologia vol 3 n 2, p 40451978

27 O Indıo Colonızado e a Politıca Indıgenısta Ofıcıal In REUNIÃO DA ASSOCIAÇÃO BRASILEIRA DE ANTROPOLOGIA 11 la78 Recife, Anars Recife 1978

28 Brasll o retrato sem retoque Livrara Francisco Alves Rıo de Janeiro, 1978

29 A Problematıca do Indıo no Brasıl Ciêncıa e Cultura Rıo de Janeiro ano 6 n 30 jul 1978

30 Pela rejexção do projeto unulateral de emancipação do indıo In ATO PUBLICO PUC SP 1979 São Paulo Anass São Paulo 9 out $/ 78$ Cadernos da Comissão Pro Indio São Paulo n 1 p 50531979 Republıcado in Cultu ral Survival Special Report n 1 p 3133 Dec/ 1979

31 O CIMI e os Antropologos Comentario ao artıgo de E Hoornaet Re 
vista Religião e Soctedade São Paulo n 3 p 204206 out /78

32 Aspectos da vida e da obra de Auguste Saınt Hularıe contribuıção a Antropologıa Flonanopolıs Conselho Estadual de Cultura p 3842 Florianopolıs 1979

33 O Combate dos Soldados de Cristo na Terra dos Papagaios Anuario Antropologico Rio de Janeiro 1978 Tempo Brasileiro Rio de Janeiro p 3313331980

34 In Memorian de Oswaldo Rodrigues Cabral Anuarıo Antropologico 1978 Tempo Brasileiro Rio de Janeuro p 3953971980 Revista de Antro pologia v2 p 1771781975

35 Indigenas Sobreviventes en el Sur del Brasil perspectivas para su des tino documentos de la segunda Reunion de Barbados Indtantdad y des colonizacion en America Latina Mexico Editorial Nueva Imagen 1979 p

\section{1}

36 Indıos do Sul do Brasıl Cadernos da Comıssão Pro Indıo A questão da emancıpação São Paulo Global edıtora p 4153 [197’]

37 O desejo dos Xokleng fugir da FUNAI Folha de S Paulo São Paulo 19 abril /81

38 Teorıa e Pesquisa em Antropologı e a Formação de Novos Pesquisado res Anais do Museu de Antropologia n 11 Florianopolıs UFSC 1980

39 Areas indıgenas ameaçadas por projetos hıdroeletrıcos no Brasıl Anaıs do Museu de Antropologia n 1215 Florianopolıs editora da UFSC 19791982 Newsletter Boston n 4 v3 p 6 Dez/1979

40 Indıgenısmo e Expansão Capıtalısta Faces da Agonıa Kaıngang Cadernos de Ciencias Sociais N 2 v 2 Florianopolıs Editora da UFSC 1981

41 Conferêncıa da ONU sobre populações indıgenas e a Terra Ciêncıa e Cultura n 3 v $34 n^{\circ} 3$ p 351353 São Paulo 1982

42 Construção de Barragens e Socıedades Indıgenas no Sul do Brasil Revista America Indigena v43 p 319342 Mexico 1983 Revista Clêncta e Cultura n 6 v 36 p 927932 jul /1984

43 Consequências da construção da barragem Machadinho para os in dios do PI Ligeiro (RS) Perspecttva Erechim RS ano 6 n 22 p 5275 set/1982

44 O Indio Perante o Direito Revista de Antropologia vol 24 p 159168 1981 Revista Clência e Cultura n 33(2) p 1611661981

45 Ensıno Gratuito Curriculo e Ideologia Revista Ciêncıa e Cultura 35(8) p 11031105 agosto/1983

46 El desarıollo hidroelectrico y los Indıgenas del Brasıl ASSOCIAÇÃO COM PAUL ASPELIN CUICUILO 13 Revista de la Escuela Nacional de Antro pologia e Historia Mexico ano 4 n 13 p 5964 abi/1984

47 Exercícıos cítıcos sobre a unuversıdade Coletânea de artıgos publıca dos em jornaıs Publicações avulsas Florıanopolıs Pro Reıtorıa de Pes quisa e Pos Graduação UFSC 1983 
48 A implantação das barragens na bacıa do no Uruguaı e suas ımphıcações socıais Comunıcação apresentada a II REUNIÃO REGIONAL DA SBPC 2 I985 Anats Blumenau I985

49 Os indıos da região sul e a construção de barragens Ptrspectıva Ere chim RS dez/1986 REUNIÃO DA ABA 15 1986, Curıtıba Ana1s Curı tıba PR mar/86 Anals do Museu de Antropologia n 18 p 112130 Floria nopolis UFSC, 1985/86

50 Questionando a Unıversidade que temos subsıdıos para a revisão da Estrutura da UFSC Cadernos de Ciências Soctais v 6 n 3 Flonanopohs 1986 Revista Educação Brasıleña ano 8 n 17 Brasılua 1986

51 Povos Indıgenas e a Constituntc Revista Ciência e Cultura 39 (2) fev/1987

52 Constıtuıção e Constıtuınte Subsıdıos Coletânea de artıgos publıca dos em jornaıs Flonianopolıs Publıcações avulsas 1987

53 Reconceituando o Pais Brasıl Luta Indigena n 31 p 910 Xanrerê CIMI reg/Sul SC dez/1987

54 'Povos Indigenas e Desenvolvimento hidreletııco na Amazônıa Revista Brastletra de Ciências Soutats v 3 n 8 p 7185 São Paulo out/88

55 Povos Indıgenas e a Nova Constıtuıção Brasıleira Revtsta de Ciências Soctais, v 2 n 1 p 4357 Porto Alegre UFRGS 1988

56 Indian Peoples and the New Brasilian Constitution Law $\theta$ Anthropolo gy Internationales Jahabuch fur Rechts anthropologie v 3 p 295306 Austria Wien 1988

57 Notas sobre hidreletricas e povos indigenas no Brasil Prieto Asuncion Paraguay Intercontinental Editora 1989 LANGDON Esther (Comp) Entre la Resignacion y la Esperança Asuncion Paraguay Intercontmen tal Editora 1989

58 Peuples Indıgenes et Developpement Hydro Electrique ETHNIES 1112 p 5663 Revue de Survival Internacional (France) 1990 Em as sociação com Aneliese Nacke

59 A barragem de Iburama e as populações atıngıdas na area indigena do cumento Denuncia Boletım de Ciências Socıals n 51/52 Depto de Crências Socials, UFSC, 1991

60 A Barragem e os Indıos Boletım de Ciencias Sociats $\mathrm{n} 52 \mathrm{p}$ 1/8 Depto de Clências Sociaus UFSC 1991

61 A Eletronorte e os Projetos Hidreletricos Hebette Rio de Janeuro Vozes/ Fase/NAEA UFPr 1991

62 O ımpacto do grande capital na Amazônı o cerco esta se fechando $\mathrm{p}$ 4651 Ruo de Janeiro Vozes/Fase/NAEA UFPr 1991

63 Projctos Hidreletricos e Povos Indıgenas na Amazônı Hebette p 7888 Rıo de Janeiro Vozes/Fase/NAEA UFPr 1991

64 Metodologia para o Estudo de Projetos de Desenvolvimento e suas implicações politıcas o caso das hidreletricas In ARANTES A RUBEM G e DEBERT G (Orgs) Desenvolvmento e Direitos Humanos A responsabih 
dade do Antropologo Campinas São Paulo Editora da UNICAMP 1992 p 91101

65 Presas y questiones socio ambientais en el Brasil Alteridades ano $2 \mathrm{n}$ 4 p 3137 Mexico 1992

66 Lıderanças Indıgenas Indıgenısmo Ofıcıal e destruıção Florestal o caso de lburama In MAGALHÃES Antônı C (Org) Soctedades Indige nas e Tiansformações Ambzentals Belem NUMA/UFPa 1993, p 185-203 67 Anuario Antropologico n 92 Rio de Janeiro Tempo Brasileiro 1994 p 89104

67 Os Direitos dos Indigenas no Brasil In SILVA Aracy L e GRUPIONI Luuz Donızete B (Org) A Tematica Indigena na Escola Brasılia DF MEC/ UNESCO/MARI 1995 pp 87105

68 O Homem do Sul In MONTEIRO Salvador e KAZ, Leonel (Org) Fronteira o Brasıl Merıdional Rio de Janeiro Edıções Alumbramento Lloyd Bank 1995 p 253275

69 Constitucion y violacion de los derechos de los pueblos indigenas en el Brasil In Grumberg Georg (coord) Articulacion de la diversidad n $17 \mathrm{p}$ 161174 Quito ediciones Abya Yala 1995

70 Constitucion y violacion de los derechos de los pueblos indigenas en el Brasıl In REUNION DE BARBADOS 3 Anals Quito 1995

71 Lideranças Indıgenas e Indıgenısmo Ofıcıal no Sul do Bıasıl Antropo logıa em Primetra Mão n 10 PPGAS UFSC 1996

72 Fnc a Liga Patriotica e os Indios In CONGRESSO DE HISTORIA DE SANTA CATARINA Flonanopolıs 1996 Anats Florianopolıs IHGSC 1996 p 704714

73 Barragens e questões Socio Ambientais no Brasll Conferência In REU NIÃO REGIONAL DE ANTROPOLOGOS DO NORTE NORDESTE 3 Anals Belem 1996 MAUES Raumundo (Org) Belem UFPA 1996, pp 1728

74 Leaders amerindiens et indigenisme gouvernemental dans le sud du Bre sil Recherches Amerindiennes au n 2 v 27 p 5160 Quebec 1997

75 Notas sobre a construção da Antropologıa no Brasıl Hoi izontes Antropo logicos Ano 3 n 7 p 6266 Porto Alegie RS 1997

76 Apresentação do livro de Orlando Sampaio Sulva Tuxa Indıos do Nordeste São Paulo Anablume 1997

77 Os Indios Xokleng e os Imigrantes In FLEURI Reinaldo Matias (Org ) Intercultura e Movimentos Socials Florianopolıs MOVER/NUP 1998 pp 5769

78 Hıdreletricas e Processo de Privatızação no Cenarıo Brasıleuro Revista de Divulgação Cultural Ano 20 n 64 Blumenau SC FURB, jan /abril de 1998

79 Notas sobre Etıca e Clência In LEITE Ilka Boaventura Etıca e Estetıca na Antropologıa Florianopolıs PPGAS UFSC/CNPq I998 p 8388

80 Santos Silvio Coelho dos Pueblos Indigenas de Brasil derechos constı tucionales tierras y luchas presentes In BARTOLOME Miguel BARA BAS Alıcia M Autonomias Etmicas y Estados Nacionales Mexico ME Cona 


\section{culta INAH 1998 p 215229}

81 Notas sobre a presença de undıgenas na Ilha de Santa Catarına In PEREIRA Nereu do Vale (Org) A tha de Santa Catarina espaço tempo e gente Florianopolis IHGSC 2002 p 83-90

82 A questão da terra e o Direito dos povos indigenas Encontros Teologicos v31 p 2335 Florianopolıs 2002

83 'Encontros de Estranhos Alem do Mar Oceano Antologia 2 Flora nopolis SC Academia Catarinense de Letras 2003 p 101 108, Revista do Centro de Estudos de Antropologia Social v7 n 2 p 431448 Lisboa, Portu gal 2003

84 A Geração Hıdrıca de Eletrıcıdade no Sul do Brasıl e seus Impactos So ciais Etnografica revista do Centro de Estudos de Antropologia Social v 7 n 1 p 87102 Lisboa Portugal 2003

85 Aunda sobre as Terras Indigenas A Noticia Jounville SC 2004 caderno 3

86 Uma viagem para alem da cristandade Revista da Academia Catarinense de Letras v 19 p 168 174, Flonanopolıs SC 2005

87 'Indıos Arredios em Joinville Joinville Onteme Hoje n 3 p 1016 Join ville SC 2005

88 'Indıos direıto e dividas A Notzcia Joinville SC 2006

$8958^{\mathrm{a}}$ Reunião Anual SBPC uma festa da ciência $A$ Noticia Flonano polıs $07 \mathrm{fev} 2006$ Jornal da ctêncta SBPC Rıo de Janeiro RJ p 3, $10 \mathrm{fev}$ 2006

90 'Aunda sobre a educação A Notıcıa Jounville 13 mar 2007 caderno 3

91 'Educação a bola da vez' A Notıcıa p 1314 Joınville 06 junho 2007 Caderno 3

92 'Ah Os indios A Notzcia p 03 Joinville 21 jun 2007

93 As cotas da UFSC A Nottcia Jomville 07 ago 2007

94 'Politica Educacional A Noticia Jomville 18 out 2007

95 'Franklın Cascaes Diarı Catarnnense Florianopolıs 31 julho de 2008

96 Turısmo e educação Dıarı Catarmense Florianopolıs 10 agosto de 2008

97 Indıan Areas Thereatened by hidroelectrıc projects in Brazl Iwrgia Do cument 44 Copenhangen Denmark 1981

98 Agostunho da Silva algumas reminuscências In EPIFÂNIO Renato (Org) et al Memoria de Agostinho da Stlva 100 anos I50 nomes Portugal Zefiro 2006

\section{Relatórios de pesquisa}

1 Coordenador Subsıdıos ao Plano Quinquenal de Educação do Estado de Santa Catarına Relatorıo CEPE Faculdade de Educação da UDESC Florianopolis 1965

2 Coordenador Sobre as condıções do Processo Educacional de Santa Ca tarına Relatorıo de Pesquisa mim CEPE Faculdade de Educação da UDESC Florianopolis 1966 
3 Supervisor Evasão e repetêncıa nas comunıdades pesqueıras de Santa Catarına mum Faculdade de Educação, Florıanopolıs, 1966

4 Supervisor Expansão da escolarıdade primarıa ate a $6^{a}$ serıe $\mathrm{mim}, \mathrm{Re}$ latorıo de Pesquisa CEPE Faculdade de Educação da UDESC Florıano polis 1968

5 Supervisor A situação do ensıno medıo em Santa Catarına mim Rela torıo de Pesquısa CEPE Faculdade de Educação da UDESC Florıanopo lis 1969

6 Projeto Xokleng Relatorıo/Termo de referêncıa SUDESUL/FUNAI/UFSC Coordenador Dezembro/1975

7 Parque Estadual do Tabuleiro Aspectos Culturass e Socıass UFSC/FAT MA Coordenador Agosto/1976

8 Projeto Urugual Os Barramentos e os Indıos Relatónı elaborado para a ELETROSUL em Convênio com a UFSC/FUNAI associado com Aspelin Paul et alı Florianopolıs mimeo 1978

9 Projeto Urugual Consequências da Barragem Machadınho para os indige nas do PI Ligeiro Coordenador Relatorio de pesquisa mimeo UFSC 1980

10Relatorıo sobre Consequências socıaıs de barragens elaborado para a GTZ/Surema Curitıba Florianopolis UFSC mans 1992

11 Relatorıo sobre a Implantação de Usinas Hıdreletrıcas e os Indıos no Sul do Brasil elaborado para a GTZ/Instituto Ambiental do Parana Curıtiba/ Flonianopolıs UFSC mans, 199597 (partıcipante)

12 Subsıdıo da Fundação Antorchas em cooperação com a CAPES, associado ao Prof Leopoldo Bartolome no valor de US 800000 para atuar como Diretor braslleiro do projeto Participacion y Resistencia em Proyetos de Gran Escala Analıse comparatıva de represas hidreletricas da Argentina Brasil y Uruguay

13 Relatorıo sobre o Estudo Etnografico da Usina Hidreletrica Machadı nho Projeto 145/98 consultoria prestada a GERASUL/Consorcio GEAM Flonanopolis SC UFSC 1998

\section{Obras}

1 Educação e desenvolvimento em Santa Catarina Florıanopolıs Imprensa Unı versitaria UFSC 1968

2 A Integração do indio na Soctedade Regional O papel dos Postos Indıgenas em Santa Catarina Florianopolıs Imprensa Unıversitarıa UFSC 1970

3 Um esquema para a educação em Santa Catarına Florıanopolıs EDEME Edı tora 1970

4 Indios e brancos no Sul do Biasll A dramatica experiência dos Xokleng 2 ed Florianopolıs EDEME 1973 Movimento/INL 1987

5 Nova historia de Santa Catarina 5 ed Florıanopolıs EDEME 19741977 $5^{\text {a }}$ Editora da UFSC, 2004

6 Educação e sociedades tribaıs Porto Alegre Movimento 1975

7 O Homem indio sobrevivente do Sul Porto Alegre Editora Garatuja, 1978 
8 Povos indigenas e a constituinte Porto Alegre /Flonanopolıs, Jomville /Edı tora da UFSC $198983 \mathrm{p}$

9 Povo e tradição em Santa Catarina Florianopolis EDEME 1971

10Ensaios sobre a economia catarinense Florianopolis EDEME 1970

11 Ensaios sobre sociologia e desenvolvimento em Santa Catarna Florianopolis EDEME 1971

12 Organizador e Co autor O Indio Perante o Diretto Ensaios Flonanopolis Editora da UFSC 1982

13 Soctedades Indigenas e o Diretto Flonianopolis Editora da UFSC 1985

140 s Indios Xokleng Memoria Visual Florianopolıs Edıtora da U F S C / UNIVALI, 1997

15 Santa Catarina no Seculo XX ensaios e memoria fotografica Florianopolıs UFSC/FCC 1999

16Memona do setor eletrico na região sul Flonanopolıs Editora da UFSC, 2002 Projeto aprovado pelo MINC Lel Rouanet (processo 096/2000)

17 Hidreletricas e Povo Indigenas Florianopolıs Letras Contemporâneas, 2003 v $1178 \mathrm{p}$

I8São Francisco do Sul muito alem da viagem de Gonneville Florianopolıs Editora da Universidade Federal de Santa Catarma 2004248 p

20 Memoria da Antropologia no Sul do Brasil Florianopolıs Editora da UFSC ABA 2006 p 208

21 Ensazos oportunos Academı Catarmense de letras Novas letras 2007192 p (Coleção ACL no 29)

220 contestado na historiografia e na literatura Flonanopolıs Academı Ca tarmense de Letras 2007

23 Hidreletricas e suas consequências sociais In VERDUM Ricardo (Org) Integração usinas hidroeletricas e impactos soctoambıentaıs Brasílı INESC 2007 p 4057

24 Kaingang no oeste catarınense tradição e atualıdades Joinville Argus 2007 pp 910 